\title{
APLIKASI METODE FUZZY MAMDANI UNTUK PEMILIHAN TEBU BERKUALITAS PADA PRODUKSI GULA
}

\author{
S.Nurmuslimah \\ Jurusan Sistem Komputer, Fakultas Teknologi Informasi, \\ Institut Teknologi Adhi Tama Surabaya \\ Jl. Arief Rahman Hakim 100 Surabaya 60117 \\ Email : puty71naura@gmail.com
}

\begin{abstract}
Abstrak
Dewasa ini, kebutuhan masyarakat akan gula selalu meningkat pertahunnya, hal ini memaksa produksi gula nasional harus ditingkatkan. Namun pada kenyataannya produksi gula nasional tetap tak mampu menuruti permintaan atau konsumsi masyarakat, sehingga pemerintah terpaksa melakukan impor gula dari negara lain. Rendahnya produksi gula nasional disebabkan oleh berbagai faktor. Diantaranya, penurunan luas areal tanam, penurunan produktivitas lahan, rendahnya rendemen industri gula nasional, serta efisiensi pabrik gula yang masih rendah. Inefisiensi yang terjadi pada pabrik gula nasional indikasinya tampak pada kualitas pasokan bahan baku tebu (rendemen) yang masih rendah. Kualitas tebu seringkali menjadi menjadi kendala dalam proses produksi gula karena proses penentuan kualitas masih menggunakan metode konvensional. Untuk membantu mengatasi permasalahan penentuan kualitas tebu, maka peneliti membangun sebuah aplikasi yang mengimplementasikan Metode Fuzzy Mamdani untuk Pemilihan Tebu yang berkualitas pada produksi gula. Dalam menentukan kualitas tebu, digunakan logika fuzzy sebagai suatu cara untuk memetakan permasalahan dari input berupa variabel Kemanisan, Kebersihan dan Kesegaran dan diproses untuk mendapat output berupa variabel status kualitas tebu. Dari hasil pengujian dan analisa perhitungan menggunakan metode FUZZY MAMDANI didapatkan nilai akurasi sistem sebesar 60\%. Hal ini terjadi karena kualitas yang didapat dari tempat survei masih mentolerir nilai ketidaksegaran karena yang diutamakan adalah berjalannya proses produksi daripada kualitas tebu yang akan diolah.
\end{abstract}

Kata Kunci: Sistem Pendukung Keputusan, Pemilihan Tebu Berkualitas, Metode FUZZY MAMDANI.

\begin{abstract}
Nowadays, the demand of sugar increases every year, consequently the national sugar production should also be increased. As a matter of fact, the domestic sugar production still cannot fulfill the society demand or consumption, therefore the government has to import sugar from other countries. The low production of domestic sugar is due various factors. Among others are the decline of planting area, the decline of land productivity, the low yield of domestic sugar industry, as well as the inneficiency of the sugar mills. The low quality of sugarcane supply (the yield) is an indication of the inneficiency in sugar mill. The sugarcane quality is often being the obstacle in the process of sugar production since the process of quality determination still uses a conventional method. In order to help overcoming this problem, an application is set up by implementing Fuzzy Mamdani Method for the selection of good quality sugarcane in sugar production. To determine the quality of sugarcane, fuzzy logic is applied as a way to map the problems from the input, i.e. sweetness, cleanliness and freshness variables and which are processed to obtain the output, i.e. the status variable of sugarcane quality. From the test result and calculation analysis, the application of FUZZY MAMDANI method can only achieve the accuracy rate of $60 \%$. This is because the quality obtainedfrom the survey area still tolerates the lack of freshness of the sugarcane, and only focuses on the production process instead of on the quality of sugarcane.
\end{abstract}

Key Words : Decision Support System, Selection of Good Quality Sugarcane, FUZZY MAMDANI Method.

\section{PENDAHULUAN}

Dewasa ini, kebutuhan masyarakat akan gula selalu meningkat setiap tahunnya, hal ini memaksa produksi gula nasional pun harus ditingkatkan.Namun pada kenyataannya produksi gula nasional tetap tak mampu menuruti permintaan atau konsumsi masyarakat, sehingga 
pemerintah terpaksa melakukan impor gula dari negara lain. Rendahnya produksi gula nasional disebabkan oleh berbagai faktor. Diantaranya, penurunan luas areal tanam, penurunan produktivitas lahan, rendahnya rendemen industri gula nasional, serta efisiensi pabrik gula yang masih rendah.

Inefisiensi yang terjadi pada pabrik gula nasional indikasinya tampak pada kualitas pasokan bahan baku tebu (rendemen) yang masih rendah. Kualitas tebu seringkali menjadi kendala dalam proses produksi gula karena proses penentuan kualitas masih menggunakan metode konvensional.

Untuk membantu mengatasi permasalahan yang telah disebutkan, maka peneliti membangun sebuah aplikasi yang mengimplementasikan Metode Fuzzy Mamdani untuk Pemilihan Tebu yang berkualitas pada produksi gula.

\section{DASAR TEORI}

\subsection{Tebu}

Tanaman Tebu (Saccharum Officanarum L) merupakan tanaman perkebunan semusim, yang mempunyai sifat tersendiri, sebab di dalam batangnya terdapat zat gula. Tebu termasuk keluarga rumput-rumputan (graminae) seperti halnya padi, glagah, jagung, bambu dan lainlain.[1]

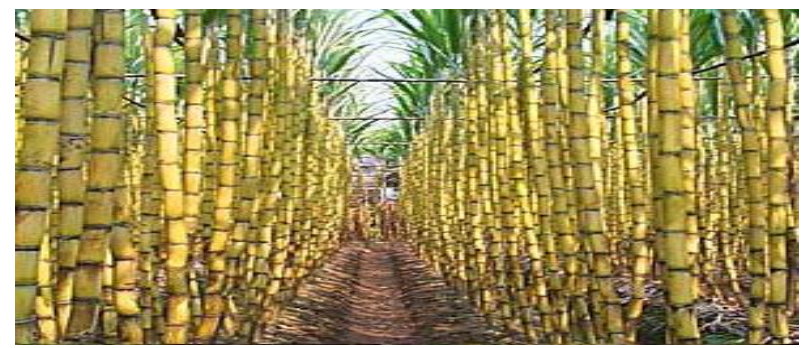

Gambar 1. Tanaman Tebu

Batang tanaman tebu beruas-ruas, dari bagian pangkal sampai pertengahan ruasnya panjang-panjang, sedangkan di bagian pucuk ruasnya pendek. Tinggi batang antara 2-5 meter, tergantung baik buruknya pertumbuhan, jenis tebu maupun keadaan iklim. Pada pucuk batang tebu terdapat titik tumbuh yang berperan penting dalam proses pertumbuhan. Akar tanaman tebu adalah akar serabut, hal ini sebagai salah satu ciri bahwa tanaman ini termasuk ke dalam kelas monocotyledone.[1]

Secara detail, klasifikasi tanaman tebu dikelompokkan sebagai berikut :[2]

Divisi : Spermatophyta

Sub divisio : Angiospermae

Kelas : Monocotyledonae

Ordo : Graminales

Famili : Graminenae

Genus : Saccharum

Spesies $\quad$ : Saccharum officinarum $L$

\section{Daur Hidup Tebu}

Daur kehidupan tanaman tebu melalui 5 fase :[3]

1. Fase Perkecambahan

Dimulai dengan pembentukan taji pendek dan akar stek pada umur 1 minggu dan diakhiri pada fase kecambah pada umur 5 minggu.

2. Fase Pertunasan

Dimulai dari umur 5 minggu sampai umur 3,5 bulan.

3. Fase Pemanjangan Batang

Dimulai pada umur 3,5 bulan sampai 9 bulan.

4. Fase Kemasakan

Merupakan fase yang terjadi setelah pertumbuhan vegetatif menurun dan sebelum batang tebu mati. Pada fase ini gula di dalam batang tebu mulai terbentuk hingga titik optimal, kurang lebih terjadi pada bulan Agustus, dan setelah itu rendemennya berangsur-angsur 
menurun. Tahap pemasakan inilah yang disebut dengan tahap penimbunan rendemen gula.

5. Fase Kematian

Fase ketika tanaman tebu tidak lagi mengalami pertumbuhan dan perlahan mati.

\section{Kualitas Tebu}

Tebu yang berkualitas adalah tebu yang memenuhi kriteria MBS (manis, bersih, segar). Manis berarti tebu sudah cukup tua atau masak dengan Faktor Kemasakan 25-30 persen, Koefisien Daya Tahan dan Koefisien Peningkatan sebesar 90-100 persen. Bersih berarti tebu terbebas dari unsur non tebu (kotoran) maksimal lima persen. Sedangkan kriteria segar secara teoritis adalah saat tebu ditebang dan digiling maksimal 36 jam, kriteria ini yang paling sulit untuk dideteksi.[4].

\subsection{Kecerdasan Buatan}

Kecerdasan didefinisikan oleh John Mc Carthy, Stanford sebagai kemampuan untuk mencapai sukses dalam menyelesaikan suatu permasalahan. Dari definisi tersebut, dapat disimpulkan kecerdasan buatan menawarkan baik media maupun uji teori kecerdasan. Teori-teori tersebut dapat dinyatakan dalam bahasa pemrograman komputer dan dapat dibuktikan eksekusinya pada komputer nyata.

Kecerdasan buatan dapat memungkinkan komputer untuk "berpikir". Dengan cara menyederhanakan program, kecerdasan buatan dapat menirukan proses belajar manusia sehingga informasi baru dapat diserap dan digunakan sebagai acuan di masa mendatang.

Terdapat dua bagian utama yang diperlukan agar dapat melakukan aplikasi kecerdasan buatan, seperti dapat terlihat pada Gambar 2.2, yaitu :[5]

1. Basis pengetahuan (knowledge base), yang berisi fakta, teori, pemikiran, dan hubungan satu dengan yang lainnya.

2. Mesin inferensi (inference engine), yang berupa kemampuan mesin untuk menarik kesimpulan berdasarkan pengalaman.

\subsection{Definisi Sistem Pendukung Keputusan}

Konsep Sistem Pendukung Keputusan (SPK) pertama kali diungkap pada awal tahun 1970-an oleh Michael S. Scott Morton dengan istilah Management Decision Sistem. Sistem tersebut adalah suatu sistem yang berbasis komputer yang ditujukan untuk membantu pengambil keputusan dengan memanfaatkan data dan model tertentu untuk memecahkan berbagai persoalan yang tidak terstruktur. Sistem pendukung keputusan adalah sebagai sebuah sistem berbasis komputer yang terdiri atas komponen-komponen antara lain komponen sistem bahasa (language), komponen sistem pengetahuan (knowledge) dan komponen sistem pemrosesan masalah.[6]

\subsection{Logika Fuzzy}

Logika fuzzy merupakan salah satu komponen pendukung soft computing. Logika fuzzy pertama kali di perkenalkan oleh Prof. Lotfi A. Zadeh pada tahun 1965. Dasar logika fuzzy adalah teori himpunan fuzzy. Pada teori himpunan fuzzy, peranan derajat keangotaan sebagai penentu keberadaan elemen dalam suatu himpunan sangatlah penting. Nilai keangotaan atau derajat keanggotaan atau membership function menjadi ciri utama dari penalaran dengan logika fuzzy tersebut.Dalam banyak hal, logika fuzzy digunakan sebagai suatu cara untuk memetakan permasalahan dari input menuju ke output yang diharapkan.

Untuk membuat sistem fuzzy, terlebih dahulu menentukan himpunan fuzzy yang akan digunakan. Himpunan fuzzy merupakan himpunan tegas (crisp), nilai keanggotaan suatu item $\mathrm{x}$ dalam suatu himpunan A, yang sering ditulis dengan $\mu_{\mathrm{A}}(\mathrm{x})$, memiliki 2 kemungkinan, yaitu :[7]

1. Satu (1), yang berarti bahwa suatu item menjadi anggota dalam suatu himpunan, atau

2. Nol (0), yang berarti bahwa suatu item tidak menjadi anggota dalam suatu himpunan. Himpunan fuzzy memiliki 2 atribut, yaitu :

1. Linguistik, yaitu penamaan suatu grup yang mewakili suatu keadaan atau kondisi tertentu dengan menggunakan bahasa alami, seperti : MUDA,PAROBAYA, TUA.

2. Numeris, yaitu suatu nilai (angka) yang menunjukkan ukuran dari suatu variabel seperti : 40, 25, 50, dsb. 
Metode Mamdani sering juga dikenal dengan nama Max-Min. metode ini diperkenalkan oleh Ebrahim Mamdani pada tahun 1975. Untuk medapatkan output diperlukan 4 tahapan, antara lain :[7]

a. Pembentukan himpunan fuzzy (Fuzzyfikasi)

b. Mengaplikasikan fungsi implikasi

c. Komposisi Aturan

d. Penegasan (defuzzyfikasi)

a)

Pembentukan Himpunan Fuzzy (Fuzzyfikasi)

Fuzzifikasi yaitu suatu proses untuk mengubah suatu masukan dari bentuk tegas (crisp) menjadi fuzzy (variabel linguistik) yang biasanya disajikan dalam bentuk himpunan-himpunan fuzzy dengan suatu fungsi kenggotaannya masing-masing.

b) Aplikasi Fungsi Implikasi

Pada metode mamdani aplikasi fungsi implikasi yang digunakan adalah fungsi Min (minimum). Secara umum digambarkan seperti pada Gambar 2:[7]

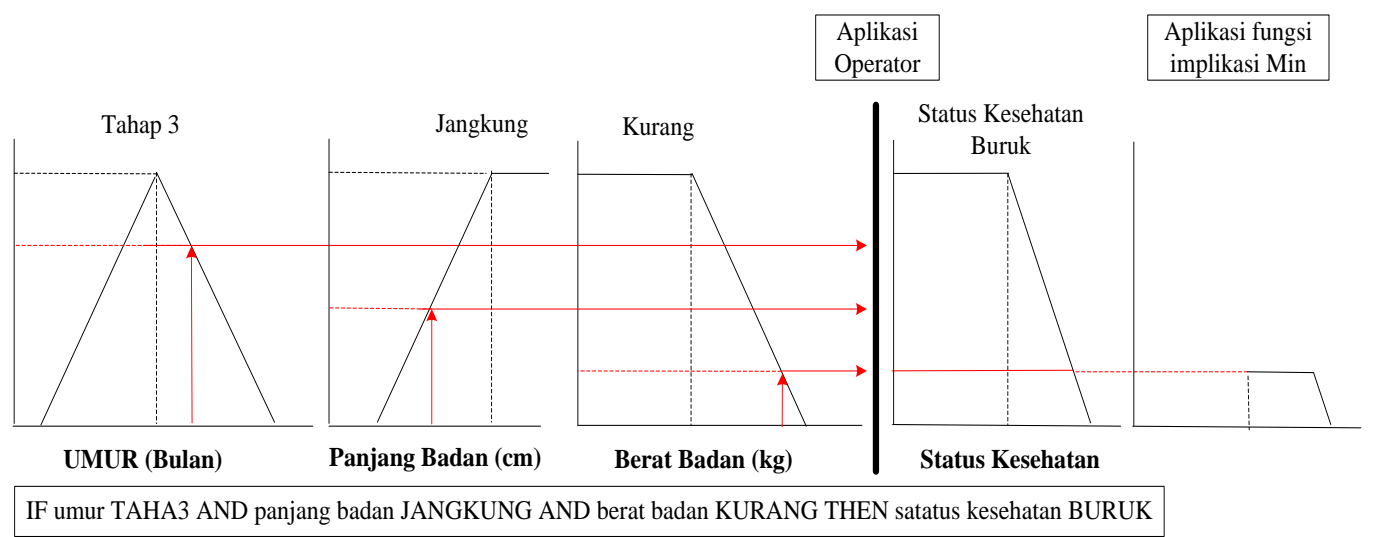

c) Komposisi Aturan

Gambar 2. Fungsi Implikasi MIN

Dari hasil aplikasi fungsi implikasi dari tiap aturan, selanjutnya pada metode Mamdani menggunakan metode Max untuk melakukan komposisi antar semua aturan.

Pada metode Max, solusi himpunan fuzzy diperoleh dengan cara mengambil nilai maksimum aturan, kemudian menggunakannya untuk memodifikasi daerah fuzzy, dan mengaplikasikannya ke output dengan menggunakan operator OR (union).

d) Penegasan (Defuzzyfikasi)

Input dari proses defuzzifikasi adalah suatu himpunan fuzzy yang diperoleh dari komposisi aturan-aturan fuzzy, sedangkan output yang dihasilkan merupakan suatu bilangan pada domain himpunan fuzzy tersebut. Sehingga jika diberikan suatu himpunan fuzzy dalam range tertentu, maka harus dapat diambil suatu nilai crisp tertentu sebagai output seperti terlihat pada Gambar 3.

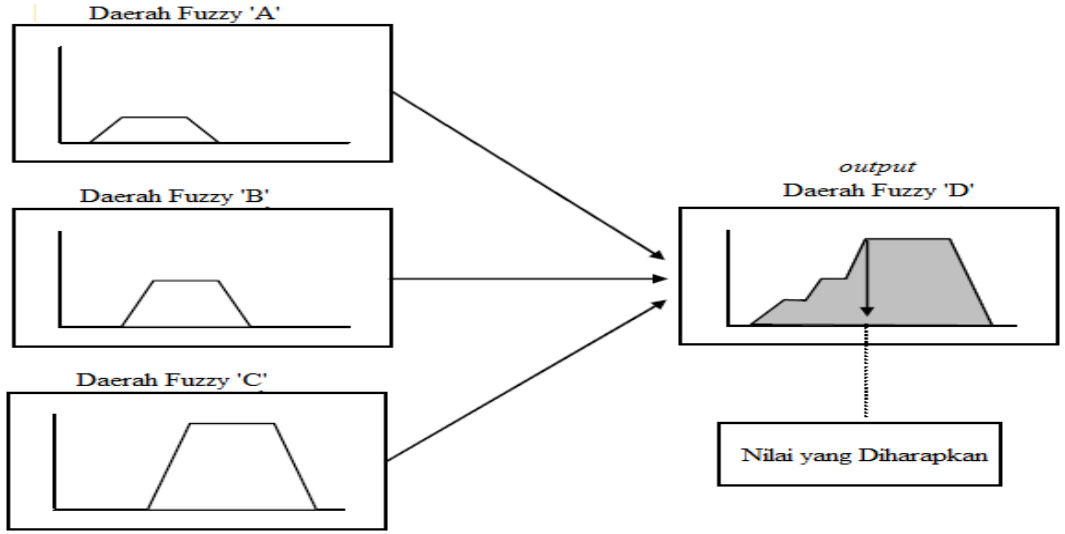

Gambar 3.Proses Defuzzyfikasi

Ada beberapa metode defuzzifikasi pada komposisi aturan mamdani, antara lain :[7] 
a. Metode Centroid (Composite Moment).

Pada metode Centroid solusi crisp diperoleh dengan cara mengambil titik pusat daerah fuzzy. Secara umum dapat dituliskan :

b. Metode Bisektor.

$$
\mathrm{Z}^{*}=\frac{\int_{a}^{b} z \mu(x) d z}{\int_{a}^{b} \mu(x) d z}
$$

Pada metode bisektor solusi crisp diperoleh dengan cara mengambil nilai pada domain yang memiliki nilai keanggotaan separuh dari jumlah total nilai keanggotaan pada daerah fuzzy.

c. Metode Mean of Maximum (MOM).

Pada metode mean of maximum solusi crisp diperoleh dengan cara mengambil nilai ratarata domain yang memiliki nilai keanggotaan maksimum.

d. Metode Largest of Maximum (LOM).

Pada metode largest of maximum solusi crisp diperoleh dengan cara mengambil nilai terbesar dari domain yang memiliki nilai keanggotaan maksimum.

e. Metode Smallest of Maximum (SOM).

Pada metode smallest of maximum solusi crisp diperoleh dengan cara mengambil nilai terkecil dari domain yang memiliki nilai keanggotaan maksimum.

\section{METODOLOGI PENELITIAN}

Analisis kebutuhan sistem merupakan langkah awal yang dilakukan untuk menunjang penerapan sistem baru, karena berkaitan dengan tujuan dari sistem baru yang akan dibuat. Fungsi dari sistem baru yang penulis rancang adalah untuk membantu menentukan tebu yang berkualitas agar PG Krembung dapat meningkatkan efisiensi produksi gula.

Berdasarkan hal tersebut diatas, dapat ditentukan bahwa diperlukan adanya suatu aplikasi yang dapat membantu dan mempermudah user-nya dalam melakukan pemilihan tanaman tebu yang berkualitas berdasarkan kriteria-kriteria tertentu dengan menggunakan metode Mamdani. Adapun kriteria-kriteria yang digunakan dalam pemilihan tanaman tebu yaitu :

1. Skala Tingkat Kemanisan

2. Tingkat Kebersihan

3. Kesegaran

\subsection{Analisis Data Sistem}

Untuk memulai pembangunan sistem diperlukan beberapa data yang dibutuhkan, data yang dibutuhkan untuk pembangunan sistem yaitu data kriteria tebu berkualitas. Data kriteria adalah data yang berisikan kriteria-kriteria yang digunakan sebagai parameter input untuk memilih tebu yang berkualitas.

\subsection{Perancangan Sistem}

Berdasar pada analisis kebutuhan sistem, maka dibuatlah diagram alir proses yang terjadi pada sistem fuzzy, yang ditunjukkan pada Gambar 4 berikut :

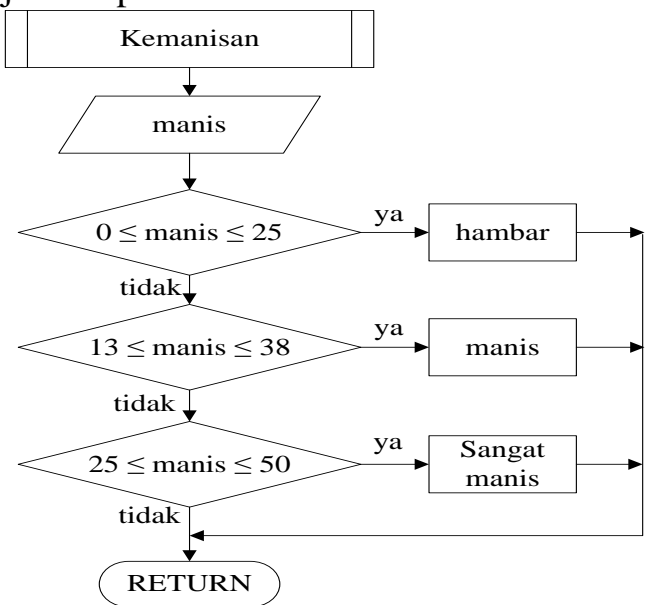

Gambar 4. Flowchart Sistem Fuzzy 


\section{1) Variabel Kemanisan}

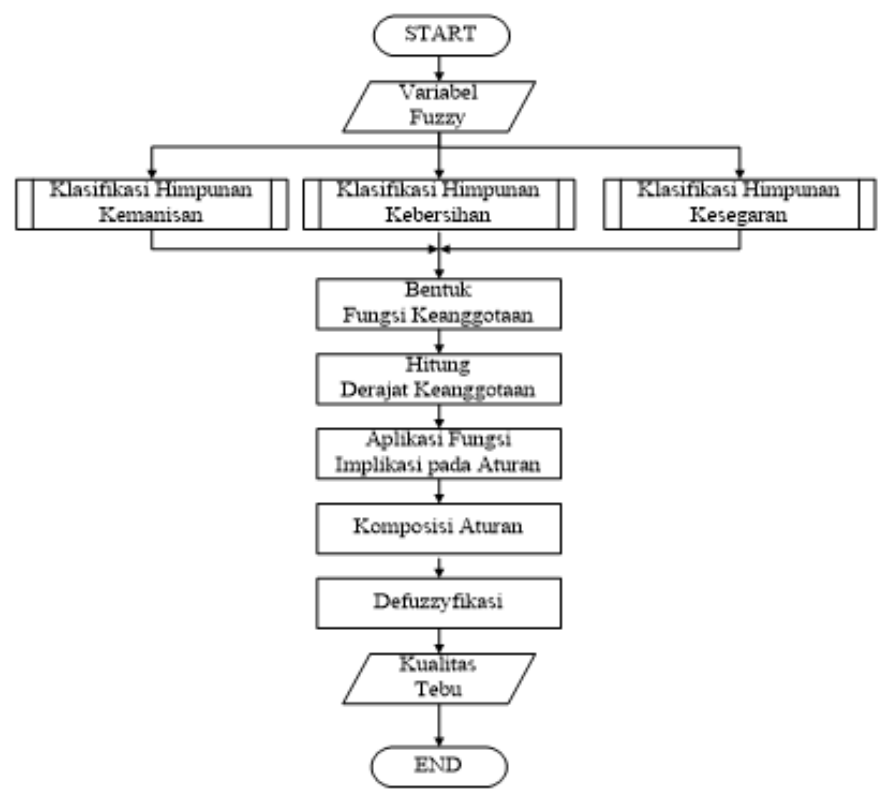

Gambar 5. Variabel Kemanisan

2) Variabel Kebersihan

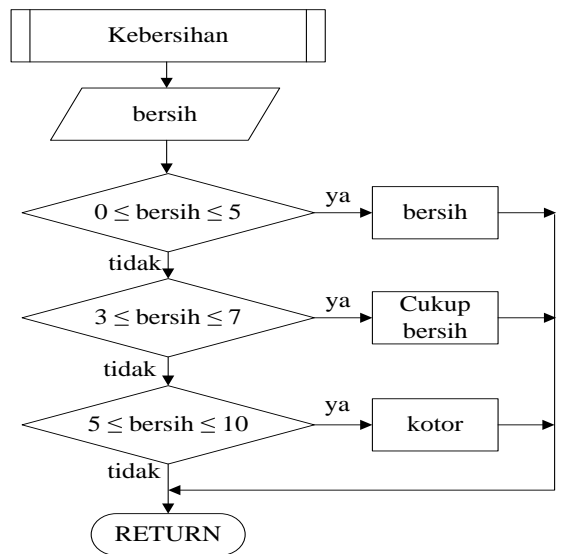

Gambar 6. Variabel Kebersihan

3) Variabel Kesegaran

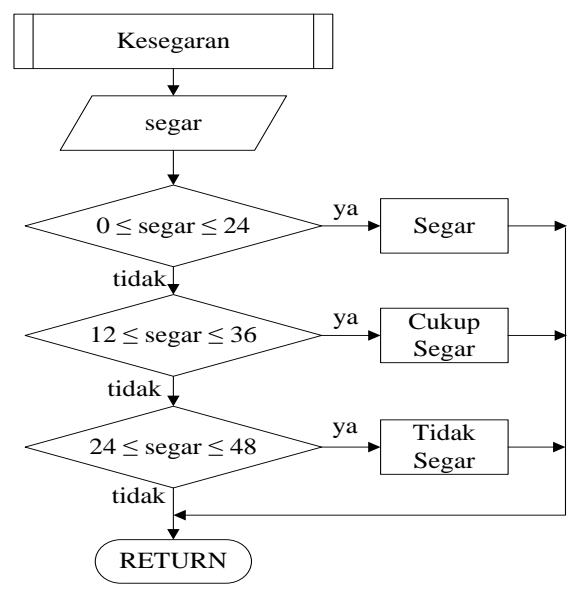

Gambar 7. Variabel Kesegaran

\subsection{Pembentukan Himpunan Fuzzy}

Pada himpunan fuzzy suatu grup yang memiliki suatu kondisi atau keadaan tertentu dalam suatu variabel fuzzy. Berikut ini adalah variabel yang di gunakan, yaitu : 
a. Variabel Kemanisan, terbagi menjadi 3 himpunan fuzzy, yaitu : hambar, manis, sangat manis.

b. Variabel Kebersihan, terbagi menjadi 3 himpunan fuzzy, yaitu : bersih, cukup bersih, kotor.

c. Variabel Kesegaran, terbagi menjadi 3 himpunan fuzzy, yaitu : segar, cukup segar, tidak segar.

d. Variabel kualitas tebu, terbagi menjadi 2 himpunan fuzzy, yaitu : bagus, dan rendah.

\subsection{Fungsi Keanggotaan}

Fungsi keanggotaan dalam aplikasi pemilihan tebu berkualitas terdiri dari :

a. Variabel Kemanisan

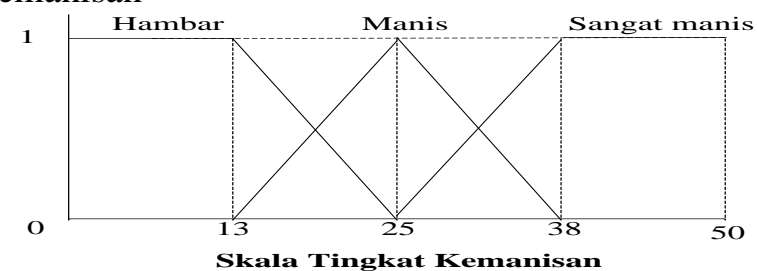

Gambar 8. Grafik himpunan fuzzy Kemanisan tebu

b. Variabel Kebersihan

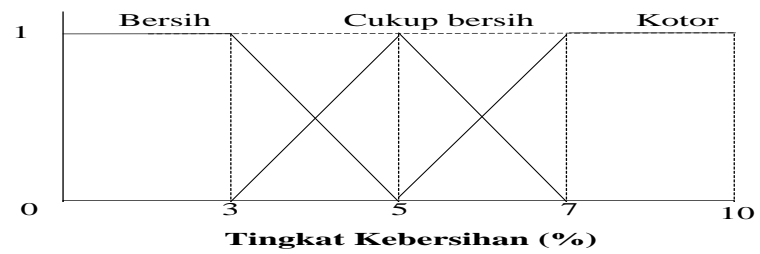

Gambar 9. Grafik himpunan fuzzy Kebersihan tebu

c. Variabel Kesegaran

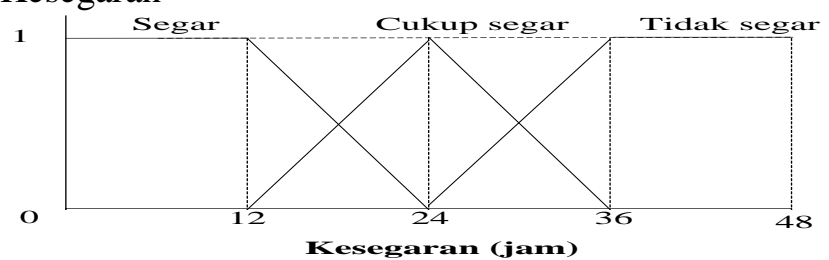

Gambar 10. Grafik himpunan fuzzy Kesegaran tebu

d. Variabel Kualitas Tebu

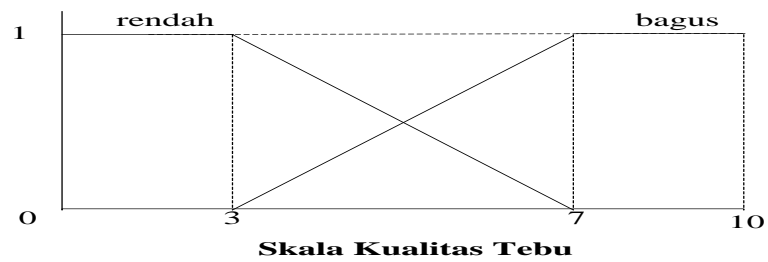

Gambar 11. Grafik himpunan fuzzy kualitas tebu

\section{HASIL DAN PEMBAHASAN}

\section{a. Halaman Login}

Gambar berikut merupakan halaman Login dengan inputan username dan password serta button Masuk untuk masuk ke dalam Halaman Utama dan mengaktifkan tombol fuzzy dan laporan. Sedang untuk login admin maka tombol petunjuk berubah menjadi edit untuk mengubah nilai parameter. 


\section{b. Halaman Fuzzy}

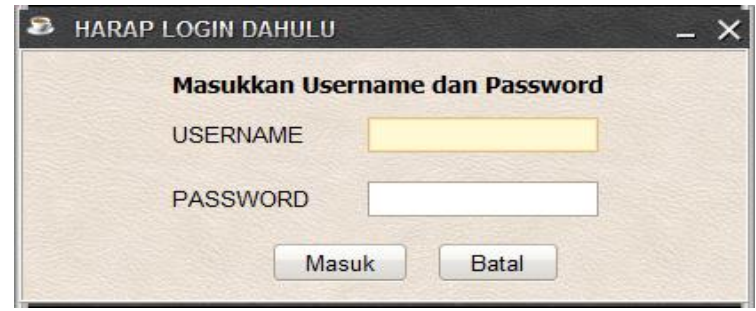

Gambar 12. Halaman Login

Halaman fuzzy merupakan halaman untuk menganalisa seluruh kriteria yang mempengaruhi kualitas tebu. Berisi textfield kemanisan, kebersihan dan kesegaran. Serta tombol untuk analisa maupun reset jika ingin mengulangi atau mengganti nilai kriteria. Dan terdapat juga textfield untuk hasil atau output dan tombol simpan untuk nantinya digunakan dalam laporan.

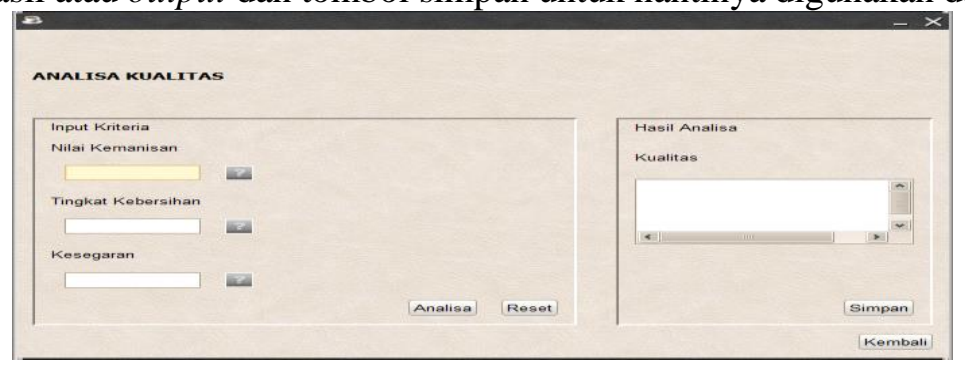

\section{c. Pengujian Sistem}

Gambar 13. Halaman Fuzzy

Setelah dijelaskan mengenai implementasi antarmuka sistem maka pada bagian ini akan dilakukan pengujian sistem. Pengujian sistem dilakukan dengan membandingkan hasil analisa secara konvensional yang dimiliki Pabrik Gula Krembung. Sistem ini dianalisa agar penerapan teori kedalam program dapat sejalan dengan kondisi asli di lapangan.Sehingga jika dihitung baik secara manual maupun dengan perhitungan program menghasilkan nilai yang tidak jauh beda.Aplikas ini diharapkan memberikan solusi atau cara baru dalam melakukan proses penentuan kualitas tebu. Berikut ini akan dijelaskan pengujian sistem dan nanti akan didapat nilai akurasi yang diperoleh dari hasil penentuan kualitas tebu yang didapat secara konvensional atau hasil penentuan kualitas tebu yang ada dalam sistem.

\section{d. Analisis Hasil}

Hasil dari perhitungan sistem harus diuji nilainya dengan melakukan perhitungan secara manual sehingga dapat dibandingkan nilainya. Contoh suatu nilai dari tiap-tiap variabel yang akan dijadikan masukan ke dalam aplikasi ini :

1. Kemanisan $=38$

2. Kebersihan $=3$

3. Kesegaran $=10$

Tahapan Perhitungan :

Pembentukan himpunan fuzzy

Masukan terdiri dari 3 variabel fuzzy, yaitu :
a. Kemanisan $=38$
b. Kebersihan $=3$
c. Kesegaran $=10$

Keluaran terdiri dari 1 variabel fuzzy, yaitu : Kualitas Tebu

Mencari nilai derajat keanggotaan.

Variabel kemanisan

Kemanisan hambar $\quad: 0-25$

Kemanisan manis $\quad: 13-38$

Kemanisan sangat manis : 25 - 50

Permintaan 34 potong berada dalam himpunan fuzzy sangat manis

$\mathrm{x} \geq 38=1 \quad \mu_{\text {manis }}[38]=1$

Variabel kebersihan

Kebersihan bersih : 0 sampai 5

\section{2 | NERO}


Kebersihan cukup bersih : 3 sampai 7

Kebersihan kotor : 5 sampai 10

Kebersihan 3 berada dalam himpunan fuzzy bersih $\quad \mathrm{x} \leq 3=1$

$\mu_{\text {kebersihan }}[3]=1$

Variabel kesegaran

Kesegaran segar $\quad: 0-24$

Kesegaran cukup segar $\quad: 12-36$

Kesegaran tidak segar $\quad: 24-48$

Kesegaran 10 berada dalam himpunan fuzzy segar $\quad \mathrm{x} \leq 12=1$

$\boldsymbol{\mu}_{\text {kesegaran }}[\mathbf{1 0}]=1$

Aplikasi Fungsi Implikasi Min tiap - tiap aturan

Pada proses apliksi fungsi implikasi ini adalah untuk mengaplikasikan implikasi pada setiap rule. Karena menggunakan metode mamdani, maka fungsi implikasi yang digunakan adalah fungsi MIN.

Komposisi aturan

Pembentukan Komposisi Aturan dilakukan dengan cara pengambilan nilai Max pada $\alpha-$ predikat. Berdasarkan hasil dari aplikasi fungsi implikasi (rule atau aturan) didapatkan nilai 1 sebagai nilai tertinggi dan 0 sebagai nilai terendah.

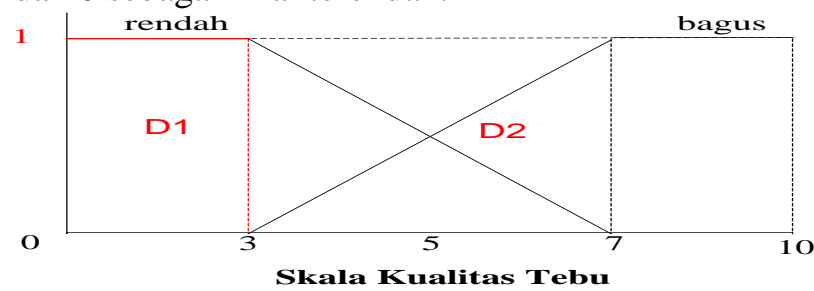

Gambar 14. Daerah Hasil Komposisi

Setelah luas setiap daerah diperoleh, selanjutnya dapat mengetahui titik pusat dengan rumus sebagai berikut :

$$
\begin{aligned}
\mathrm{COA} & =\frac{\mathrm{M} 1+\mathrm{M} 2+\mathrm{M} 3}{D 1+\mathrm{D} 2+\mathrm{D} 3} \\
& =\frac{4.5+8.668+0}{3+2+0} \\
& =\frac{13.168}{5} \\
& =2.6333
\end{aligned}
$$
tebu rendah

Jadi, hasil dari titik pusat diperoleh 2.633 maka hasil pemeriksaan menyatakan kualitas

\section{KESIMPULAN}

1. Implementasi Metode Logika Fuzzy Mamdani dapat menjadi pertimbangan pengambil keputusan dalam memilih tebu berkualitas yang akan diproduksi.

2. Hasil dari pengujian sistem nilai akurasinya $60 \%$. Hal ini terjadi karena kualitas yang didapat dari tempat survei masih mentolerir nilai ketidak segaran karena yang diutamakan adalah berjalannya proses produksi dari pada kualitas tebu yang akan diolah

\section{Daftar Pustaka}

[1] Supriyadi, Ahmad. (1992). "Rendemen Tebu dan Liku-Liku Permasalahannya". Yogyakarta: Kanisius.

[2] Suwarto, YukeOctavianty. (2012).” Budidaya 12 Tanaman Perkebunan Unggul”. Jakarta : $\quad$ Penebar Swadaya.

[3] http://www.kppbumn.depkeu.go.id/Industrial_Profile/PK4/Profil\%20Tebu1 files/page 0001.htm diakses tanggal 30 April 2014.

[4] Mubyarto \& Daryanti. (1991). "Gula Kajian Sosial-Ekonomi". Yogyakarta : Aditya Media. 
[5] Kusumadewi, Sri. (2002). “Artificial Intelligence (Teknik dan Aplikasinya)”. Yogyakarta : $\quad$ Graha Ilmu.

[6] Turban, Efraim \& Aronson, Jay E. (2001). "Decision Support Systems and Intelligent System $\left(6^{\text {th }} e d\right)$ ”. Prentice Hall : Upper Saddle River, NJ.

[7] Kusumadewi, Sri, \& Hari Purnomo. (2010). "Aplikasi Logika Fuzzy untuk Pendukung Keputusan (Edisi 2)". Yogyakarta : Graha Ilmu. 